\title{
A EXPANSÃO CONSERVADORA DOS CURSOS DE FORMAÇÃO DE PROFESSORES EM CIÊNCIAS SOCIAIS EM SANTA CATARINA
}

\section{THE CONSERVATIVE EXPANSION OF TEACHER TRAINING COURSES IN SOCIAL SCIENCES IN SANTA CATARINA}

\author{
Amurabi Oliveira*
}

\section{Introdução}

A análise acerca do Ensino Superior no Brasil tem sido um dos motes principais da Sociologia da Educação que aqui tem se desenvolvido nas últimas décadas, o que vem sendo demonstrado pelos balanços bibliográficos que recentemente têm sido realizados na área (NEVES, 2002; MARTINS; WEBER, 2010; OLIVEIRA, 2013c), propulsionados pela ampliação do acesso a esse nível de ensino, que por sua vez tem um impacto direto nos desdobramentos que passa a sofrer o campo da Sociologia da Educação (ISAMBERT-JAMATI; MAUCORPS, 1972), como pode ser verificado pelo crescimento de grupos de pesquisa registrados no diretório do CNPQ a partir dos anos 2000 (OLIVEIRA; SILVA, 2014).

0 presente trabalho tanto visa a contribuir para o debate no campo da Sociologia da Educação no Brasil de forma geral, como de modo particular para as discussões que têm sido desencadeadas em torno do Ensino de Sociologia, que vem se consolidando por meio da publicação de artigos científicos, coletâneas, grupos de trabalhos, grupos de pesquisa, teses e dissertações (ERAS, 2014; NEUHOLD, 2014).

0 título deste artigo, traz desde o princípio, as duas ideias principais que buscarei demonstrar: a) que ocorreu após a reintro-

*Doutor em Sociologia pela Universidade Federal de Pernambuco (UFPE). Professor da Universidade Federal de Santa Catarina (UFSC/Florianópolis/SC/Brasil) atua em seu Programa de Pós-Graduação em Sociologia Política. Pesquisador do CNPq.amurabi_cs@hotmail.com. 
dução da Sociologia no currículo do Ensino Médio em nível nacional, cujo marco é a promulgação da Lei $n^{\circ} 11.684 / 08$, um significativo impacto sobre os cursos de formação de professores de Ciências Sociais ${ }^{1}$, que têm se expandido significativamente nesse curto intervalo de tempo; b) que essa expansão tem se dado de forma conservadora, assentada principalmente no ensino privado e mais recentemente na Educação a Distância (EAD).

As duas ideias aqui defendidas possuem naturezas distintas, pois ao passo que a primeira é um dado quantitativo facilmente verificável a partir do material fornecido pela plataforma e-mec <http://emec.mec.gov. br/>, a segunda possui um caráter valorativo e avaliativo. Nesse sentido, é importante deixar claro que compartilho a posição defendida por Martins (2009, p. 29) de que:

0 funcionamento do ensino privado de perfil empresarial, regido pelo livre jogo do mercado, transformou um direito da cidadania moderna num privilégio individual, convertendo sua clientela em consumidores de produtos educacionais, impondo pesados custos financeiros e humanos a uma parte expressiva dos seus estudantes.

De tal forma, que o modo como têm se dinamizado os cursos de formação de professores de Ciências Sociais no Brasil, e em Santa Catarina (SC) particularmente, apon- ta para essa direção, o que na minha leitura implica uma expansão conservadora que não apresenta um processo de democratização do ensino.

Apesar de compreender que esse processo tem se dado de forma bastante geral no Brasil, é importante destacar que há singularidades. Por exemplo, no Nordeste os cursos presenciais criados a partir de 2008 são todos públicos (OLIVEIRA, 2014a). Sendo assim, ao me voltar para a realidade de SC tento ao mesmo tempo captar as questões que se aplicam a outros cenários, e por outro lado destacar as singularidades encontradas. 0 objetivo deste trabalho é, dentro de seus limites, analisar o processo de expansão do número de cursos de formação de professores de Ciências Sociais no estado de Santa Catarina, a partir de 2008.

Para uma melhor compreensão por parte do leitor apresentarei o texto em mais quatro partes; na primeira tratarei de realizar uma sucinta análise sobre a formação de professores em Ciências Sociais no Brasil de forma geral; depois contextualizarei o Ensino de Sociologia em Santa Catarina, cuja retomada no currículo escolar se deu dez anos antes da obrigatoriedade nacional; logo em seguida explanarei sobre o cenário que havia nesse campo até 2007; por último, realizarei uma análise sobre o processo de expansão que ocorreu a partir de 2008, considerando principalmente o perfil dos cursos que emergem a partir desse momento.

1. É importante frisar que apesar de a disciplina que existe no Ensino Médio ser a Sociologia os cursos de formação de professores que habilitam os docentes para lecioná-la são os de Ciências Sociais, ainda que haja um movimento recente de criação de cursos específicos em Sociologia, como poderá ser verificado no decorrer deste trabalho; sendo assim, utilizarei de forma mais recorrente a referência às Ciências Sociais, considerando a tradição intelectual que se constituiu aqui no Brasil, bem como o fato de o termo ser mais abrangente. 


\section{A formação de professores em Ciências} Sociais

Inegavelmente as discussões sobre a formação docente no Brasil assumiram novos contornos a partir da chamada Nova Lei de Diretrizes e Bases da Educação (LDB) - lei $n^{\circ}$ 9.394/96 - tendo em vista que:

A Lei n. 9.394/1996, denominada Nova LDB, introduz uma inflexão na questão ao substituir a expressão profissional do ensino, que remete a uma visão nitidamente conteudística, pela expressão profissionais da educação, a qual, além dos conteúdos e de suas tecnologias a serem ministrados em processos formativos, enfatiza a dimensão política e social da atividade educativa, e inclui a dinâmica escolar, o relacionamento da escola com o seu entorno mais amplo, a avaliação, a gestão. (WEBER, 2003, p. 1132)

Portanto, há de se considerar também tais aspectos políticos para uma análise mais apurada dos processos formativos em questão. Somada a essas questões é importante frisar o lugar secundário que as licenciaturas têm ocupado junto aos cursos de Ciências Sociais historicamente (MORAES, 2003), o que em parte pode ser explicado pelo redirecionamento que foi ocorrendo em tais cursos para as atividades de pós-graduação, especialmente a partir dos anos de 1970 quando surge no país o atual formato dos cursos de mestrado e doutorado, desdobrando-se num verdadeiro "insulamento acadêmico" da discussão sobre o ensino de Sociologia (SARANDY, 2012), e por consequência da formação de professores.

Outro aspecto que é importante frisar diz respeito à persistência do chamado modelo “ $3+1$ ” na formação de professores $^{2}$, que continua a se fazer presente em inúmeros cursos de Ciências Sociais Brasil afora (HANDFAS, 2009). Mesmo quando esse modelo não se coloca de forma explícita se faz presente de modo implícito, considerando-se que, por vezes, há um parco ou inexistente diálogo entre as disciplinas teóricas e aquelas tidas como pedagógicas (DINIZ-PEREIRA, 1999; OLIVEIRA, 2014b). Entretanto,

Esse cenário tem se modificado sensivelmente com o processo de reintrodução da Sociologia no currículo escolar por meio do Parecer CNE/CBE no 38/06 e com a lei $n^{\circ}$ 11.684/08, uma vez que implicou tanto na necessidade dos atuais cursos de Ciências Sociais repensarem a formação de professores, quanto numa ampliação considerável do número de licenciaturas nessa área, com destaque para a expansão universitária pública. Mas ainda há impasses que não se encontram resolvidos, pois, se por um lado as Diretrizes Curriculares para os Cursos de Ciências Sociais (2001) reconhecem a necessidade de haver competências e habilidades próprias ao licenciado, quais sejam: a) domínio dos conteúdos básicos que são objeto de ensino e aprendizagem no ensino fundamen-

2. Nos anos de 1930, surgiram os primeiros cursos de formação de professores em nível superior, e somente a partir de 1939 com a criação da Universidade do Brasil, que contava com a Faculdade Nacional de Educação, é que se passou a criar as licenciaturas dentro do modelo que se convencionou denominar como "3+1", no qual deveria se cursar primeiro um curso de bacharelado e posteriormente complementá-lo com uma formação pedagógica, para assim habilitar o egresso para a docência; esse modelo se estendia inclusive ao curso de pedagogia (SAVIANI, 2011). 
tal e médio; b) domínio dos métodos e técnicas pedagógicos que permitem a transposição do conhecimento para os diferentes níveis de ensino; estas esbarram no fato de não haver clareza sobre quais são os conteúdos básicos a serem lecionados na Educação Básica, o que se deve à ausência de um currículo nacional (OLIVEIRA, 2013a), bem como na falta de tradição da disciplina no currículo escolar. (OLIVEIRA, 2013a, p. 146).

No bojo dessas transformações, a introdução da Sociologia no Programa Nacional do Livro Didático (PNLD) a partir de 2012, bem como o advento do Programa Institucional de Bolsas de Iniciação à Docência (PIBID), têm sido algumas das ações que têm dinamizado essa realidade, o que tem se substanciado também na produção acadêmica na área.

No caso do PIBID, o programa tem ocupado um relevante papel no processo de aproximação entre as Universidades e a Escola, bem como para o próprio Estágio Supervisionado que tende a ser redimensionado ante esse novo cenário, levando a um acúmulo de conhecimento acerca de uma realidade até então pouco explorada no campo das Ciências Sociais (OLIVEIRA; LIMA, 2013).

Além do parco interesse dos cientistas sociais pela educação, há uma aparente “divisão de tarefas" entre a Sociologia da Educação desenvolvida pelas Faculdades de Educação e a realizada junto aos Departamentos de Sociologia/Ciências Sociais, pois, ao passo que aquela estaria mais direcionada para a investigação sobre a Edu- cação Básica, esta se voltaria majoritariamente para o Ensino Superior (MARTINS; WEBER, 2010).

Afirmo, portanto, que apesar de permanecer como algo marginal dentro do campo acadêmico das Ciências Sociais, o debate sobre o Ensino de Sociologia, e sobre a formação de professores em Ciências Sociais de modo mais específico, tem sofrido sensíveis e consideráveis alterações, ganhando relevância. Afınal, parte de seu desprestígio deveu-se à intermitência da Sociologia no currículo escolar (SILVA, 2010; CARVALHO FILHO, 2013; OLIVEIRA, 2013b), e a valorização da licenciatura junto aos Departamentos de Sociologia/Ciências Sociais passa, necessariamente, pela compreensão acerca da relevância da Sociologia como componente curricular na Educação Básica, e pela sua consequente presença no currículo, bem como pela valorização do trabalho docente ${ }^{3}$.

\section{0 ensino de Sociologia em Santa Catarina}

Apesar do retorno da Sociologia ser algo recente no currículo escolar em nível nacional, desde o processo de redemocratização da sociedade brasileira, e do fim da profıssionalização compulsória do Ensino Médio, alguns estados pontualmente iniciaram um processo de reintrodução dessa disciplinar escolar, entre eles Santa Catarina que, a partir de 1998, passou a contar com essa disciplina, o que se deu por meio da Lei Complementar Estadual no 173/98, que deu nova redação ao parágrafo único

3. Nesse tópico não busquei realizar uma análise minuciosa do debate em torno da formação docente em Ciências Sociais no Brasil, tendo em vista o foco e os limites deste trabalho. Para uma melhor análise acerca dessa questão vide Handfas (2012), Takagi (2013), Oliveira (2013a). 
do artigo 41, da lei $\mathrm{n}^{\circ} 170 / 98$, que dispõe sobre o sistema estadual de educação ${ }^{4}$.

Todavia, podemos encontrar registros que apontam para uma movimentação anterior em torno do Ensino de Sociologia no Estado. Ao final do IV Congresso Catarinense de Sociologia - evento organizado pela Sociedade Catarinense de Sociologia que fora fundada em $1972^{5}$ (CARVALHO; MATTOS, 2005) -, realizado entre 30 de maio e $1^{\circ}$ de junho de 1980 na Universidade do Planalto Catarinense (UNIPLAC), na cidade de Lages, houve a aprovação de algumas moções por deliberação da Assembleia Geral da Sociedade Catarinense de Sociologia; dentre elas estava a moção "Pela reintrodução das disciplinas de Sociologia e Filosofia nos currículos de $2^{\circ}$ graus" (UFSC, 1980).

Esse tipo de ação indica que a preocupação com a presença da Sociologia na Educação Básica estava sendo pautada no debate acadêmico local, possivelmente em articulação com as discussões que vinham sendo realizadas em outras unidades da federação, que também indicavam um movimento que compreendia o retorno da Sociologia ao currículo escolar como relevante.

É inegável que a reintrodução no nível estadual trouxe avanços que foram sendo galgados paulatinamente, como a realização do I Encontro Regional de Sociologia, que teve como um dos marcos a criação do Laboratório Interdisciplinar de Ensino de Filosofia e
Sociologia (LEFIS), que iniciou suas atividades em 2004 no Colégio Estadual Simão José Hess, localizado no bairro Trindade, em Florianópolis. Segundo Coan (2006, p. 90):

[...] o sentido da criação do LEFIS está apontando para uma cultura nova, uma nova perspectiva, levando em conta o conjunto de pessoas envolvidas no processo educacional. Professores das universidades e do ensino médio, bem como alunos, em atividades de ensino, de formação, de promoção de eventos e elaboração pedagógica e didática, têm no LEFIS, mais que um espaço físico, um espaço de relação e crescimento e fortalecimento das humanidades.

Em Santa Catarina, o LEFIS representou a possibilidade de construção de um diálogo profícuo entre a Universidade e a Secretaria de Educação, o que impactou também as diretrizes curriculares estaduais. Segundo a análise de Caridá (2014, p. 113):

Com relação à perspectiva comparativa entre universidade e escola entendo que no caso das regiões norte e nordeste, apesar de haverem professores universitários envolvidos com a pesquisa e extensão no âmbito da educação básica, parece faltar diálogo entre academia e secretarias estaduais de educação. Isto porque as diretrizes curriculares foram construídas sem levar em consideração a

4. Em Santa Catarina devemos destacar que foi no Instituto de Educação de Florianópolis, ainda nos anos de 1930, que a Sociologia foi introduzida, tendo sido essa uma das primeiras Escolas Normais do país a contar com essa disciplina em sua composição curricular, o que nos indica, conforme Daros et al (2000), que havia sintonia das discussões tidas no Estado quanto à importância da disciplina na formação docente com as discussões existentes nos principais centros culturais do país.

5. Essa era uma sociedade de caráter acadêmico, diferindo, portanto, da Associação Profissional dos Sociólogos de Santa Catarina, fundada em 1984. Interessante perceber que, ao passo que em nível nacional foram as associações profissionais que capitanearam num primeiro momento a discussão em torno do retorno da Sociologia ao currículo escolar (MORAES, 2011), em Santa Catarina apenas encontramos registros nessa direção por parte da Sociedade Catarinense de Sociologia, de caráter acadêmico. 
experiência adquirida no meio universitário e o contato com os professores da educação básica. Já nas demais regiões (Centro-Oeste, Sudeste e Sul) este diálogo está mais fecundo $\mathrm{e}$ as diretrizes curriculares mais bem elaboradas, independente da escolha política à qual elas se vinculam.

Concordo parcialmente com a análise realizada pela autora, pois, por um lado, de fato pode-se perceber uma maior convergência entre o que é posto nas diretrizes estaduais e o debate acadêmico nas regiões Sul e Sudeste, mas por outro há de se considerar que nesses estados, via de regra, a reintrodução da Sociologia se deu em um período anterior com relação ao resto do país, o que possibilitou que houvesse outro tempo de maturação desse debate.

Apesar dos avanços que transcorreram, ao que me parece a legislação estadual não teve força suficiente para alavancar mudanças mais profundas, pois boa parte dos docentes que atua lecionando Sociologia possui formação em outras áreas do conhecimento (ROSA, 2009; JINKINGS, 2011), o que é uma tendência que se coloca em nível nacional.

Outro indicador que podemos utilizar para pensarmos os limites da legislação estadual diz respeito ao fato de que apenas um novo curso presencial de Ciências Sociais/Sociologia voltado para a formação de professores surgiu entre os anos de 1998 e 2007, o que aponta para a manutenção quase inalterada do cenário de formação docente nessa área.

Volto a frisar que não nego com isso o avanço que a legislação estadual trouxe; foi um avanço relativo, cuja importância não pode ser negada, porém que não pode ser analisado sem considerar os limites de sua capacidade de impactar o campo de modo mais amplo, o que inclui os espaços de formação docente.

\section{A formação de professores em Ciências Sociais em Santa Catarina até 2007}

\section{A literatura da Sociologia da Educação} no Brasil tem apontado claramente para o processo de expansão do Ensino Superior que se inicia a partir dos anos de 1970, e que ganha um novo fôlego a partir de meados dos anos de 1990 (NEVES, 2002). Esse fenômeno foi acompanhado de uma diversificação da oferta de modelos institucionais. Ou seja, o ensino universitário no seu sentido estrito ${ }^{6}$ deixou de ser o predominante, passando a ganhar espaço nesse momento os cursos ofertados por faculdades isoladas e centros universitários, o que foi capitaneado principalmente pelo setor privado.

6. 0 que caracteriza essencialmente o ensino universitário é o desenvolvimento de forma articulada do ensino, da pesquisa e da extensão. Em termos formais são exigidos os seguintes critérios para que uma instituição de ensino superior no Brasil seja considerada uma universidade de acordo com a Resolução CNE/ CES no 3/2010: 1) Um terço do corpo docente em regime de tempo integral; 2) Conceito Institucional (CI) igual ou superior a quatro na última avaliação institucional externa do Sistema Nacional de Avaliação da Educação Superior (SINAES); 3) Índice Geral de Cursos (IGC) igual ou superior a quatro na última divulgação oficial do Instituto Nacional de Estudos e Pesquisas Educacionais Anísio Teixeira (INEP); 4) 0ferta regular de, no mínimo, 60\% dos cursos de graduação reconhecidos ou em processo de reconhecimento; 5) Oferta regular de, pelo menos, quatro cursos de mestrado e dois de doutorado reconhecidos pelo MEC; 6) Compatibilidade do plano de desenvolvimento institucional (PDI) e do estatuto com a categoria de universidade; 7) A instituição e seus cursos não podem ter sofrido, nos últimos cinco anos, penalidades descritas no artigo 46 da Lei de Diretrizes e Bases da Educação (LDB), Lei n 9394/1996. 
Acredito que os cursos de Ciências Sociais, especialmente na modalidade da licenciatura, possuem uma trajetória bastante sui generis se comparados com esse cenário mais geral que se desenhou no Brasil nesse período. Pois, no momento de maior e mais rápida expansão do Ensino Superior, seu número de graduações ofertadas pouco se alterou, o que reflete, em minha avaliação, a ausência de um campo de atuação claro dos egressos do curso de Ciências Sociais, se considerarmos o bacharelado ou, mais ainda, a licenciatura, dada a ausência da Sociologia nos currículos escolares nesse momento.

Compreendo dessa forma, que a questão do ensino de Sociologia na Educação Básica deve ser analisada como uma preocupação que não diz respeito exclusivamente aos cursos de formação de professores, mas ao campo acadêmico das Ciências Sociais como um todo, tendo em vista que a presença ou ausência dessa ciência no currículo escolar possui um impacto sobre a existência de um maior ou menor número de cursos de graduação nessa área.

Em Santa Catarina, o primeiro curso de Ciências Sociais, dentre os que continuam em funcionamento, foi aquele criado pela Universidade Federal de Santa Catarina em $1973^{7}$, que voltou-se desde o seu princípio para a pesquisa e o ensino (LÜCHMANN, 2002), havendo inicialmente entre os professores que lecionavam as disciplinas das Ciências Sociais, historiadores, economistas, juristas, filósofos etc., o que se refletia também no nível da formação ofertada, tendo em vista que:
0 primeiro currículo contemplava áreas de conhecimento e disciplinas como museologia, folclore, arqueologia, antropologia, sociologia da educação e ciência política. A antropologia já nesta época apresentava certa maturidade acadêmica, ressaltando-se a erudição e o denodo de Oswaldo Rodrigues Cabral e Silvio Coelho dos Santos. (UFSC, 2006, p. 9-10)

A articulação entre o ensino e a pesquisa em tal curso pode ser percebida ainda quando se considera o advento da pós-graduação na área; em 1976 foi criada uma especialização em Ciências Sociais com duas áreas de concentração, Sociologia e Antropologia, e em 1978 um mestrado com as mesmas áreas. Em 1985 criaram-se os mestrados em Sociologia Política e Antropologia Social, e em 1999 tais programas passaram a contar também com cursos de doutorado.

0 segundo curso de Ciências Sociais dentre os que estão ainda em funcionamento foi criado junto à Universidade Regional de Blumenau (FURB) em 1987. Até o início dos anos 2000 esses eram os únicos cursos de formação de professores de Ciências Sociais em Santa Catarina, o que nos leva às seguintes considerações: a) a reintrodução da Sociologia no currículo escolar por meio da Lei Complementar Estadual em 1998 não teve um impacto imediato sobre o advento das licenciaturas em Ciências Sociais; b) nesse primeiro momento tais cursos estavam alocados exclusivamente em instituições universitárias e públicas ${ }^{8}$.

Volto, portanto, a minha hipótese de que no momento em que o Ensino Superior Bra-

7. 0 curso foi criado em 1973, porém reconhecido em 1978 por meio do decreto presidencial no 81.144 .

8. A FURB é uma instituição pública municipal; segundo informações do site <http://emec.mec.gov.br/> sua categoria administrativa seria "Especial”, o que significa que, apesar de pública, não é gratuita. 
sileiro estava marcado pela rápida expansão do setor privado e pelas instituições não universitárias os cursos de Ciências Sociais caminhavam na contramão desse processo.

Apesar de não ter provocado impactos de forma imediata, a partir de 1998 a reintrodução da Sociologia em nível estadual, articulada com outras iniciativas como demonstrado no tópico anterior, possibilitou que houvesse um crescente incremento na oferta de cursos de Ciências Sociais voltados para a formação docente.

Em 2003, tal curso foi criado junto à Universidade do Contestado (UC), na cidade de Canoinhas, e a partir de 2005 surgiram ainda aqueles ofertados na modalidade da Educação a Distância (EAD), primeiramente junto à Universidade Luterana do Brasil (ULBRA), posteriormente pelo Centro Universitário Leonardo Da Vinci (UNIASSELVI) em 2006 - neste caso utilizando a denominação de licenciatura em Sociologia -, e ainda em 2007 junto à Universidade Castelo Branco (UCB).

Nesse momento já podemos perceber uma mobilização que se acentua a partir da Resolução CNE/CEB n 38/06, que indicou a obrigatoriedade da Sociologia no currículo do Ensino Médio, tendo em vista que metade dos cursos que surgiu a partir dos anos 2000 é posterior a tal resolução. Também é a partir desse momento que as instituições privadas se fazem presentes, bem como os cursos da modalidade EAD; com relação a essa modalidade, devido aos limites deste trabalho não realizarei uma análise pormenorizada. Porém é necessário deixar registrado que em minha percepção há um claro hiato entre a forma como se produz conhecimento nas Ciências Sociais, marcada pelo acesso aos textos de autores clássicos e contemporâneos de forma articulada com a pesquisa, e como tem se desenvolvido a
EaD no Brasil, o que acaba por fragilizar tal formação, o que é aprofundado ainda mais pela tradição ainda incipiente que a área do conhecimento possui nessa modalidade de ensino (OLIVEIRA, BRUM, 2014).

Se considerarmos apenas os cursos presenciais anteriores à reintrodução em nível nacional, considerando como marco a Lei $\mathrm{n}^{\circ}$ 11.684/08, havia em Santa Catarina apenas três cursos de formação de professores na área das Ciências Sociais. Desses cursos, apenas um surgiu após a reintrodução em nível estadual, e concentravamse exclusivamente no ensino universitário majoritariamente em instituições públicas de ensino, o que aponta para uma posição singular no campo universitário brasileiro, tendo em vista os aspectos que são assumidos nesse período.

\section{0 cenário que surgiu a partir da lei $n^{\circ}$ 11.684/08: a expansão conservadora}

A reintrodução da Sociologia em nível nacional delineou mais claramente o campo de atuação dos egressos da licenciatura em Ciências Sociais, e acredito que isso impactou mesmo as Unidades da Federação que já haviam introduzido essa disciplina no currículo por meio da legislação local.

Analisando os dados disponíveis fica evidente tal questão, tendo em vista que foram criados cursos de licenciatura em Ciências Sociais junto às seguintes instituições: Universidade Federal da Fronteira Sul (UFFS) em Chapecó - 2010; Centro Universitário para o Desenvolvimento do Alto Vale do Itajaí (UNIDAVI) em Rio do Sul - 2009; Universidade Comunitária para a Região de Chapecó (UNOCHAPECÓ) em Chapecó - 2009; Universidade da Região de Joinville (UNIVILLE) em Joinville - 2009; Universidade do Oeste de Santa Catarina 
(UNOESC) em São Miguel do Oeste - 2012; Universidade do Sul de Santa Catarina (UNISUL) em Araranguá - 2014; e a UC, que criou um novo curso na cidade de Mafra em 2014, em Sociologia. Além do mais, a Universidade do Norte do Paraná (UNOPAR) passou a oferecer a partir de 2014 a licenciatura em Sociologia na modalidade EaD em diversos polos do estado.

Deve-se abrir um parêntese para o fato de que parte desses cursos surgem como parte do Plano Nacional de Formação de Professores da Educação Básica (PAFOR) ${ }^{9}$, portanto, ainda que a plataforma e-MEC não especifique isso, podemos observar ao analisarmos os últimos editais dos vestibulares das instituições citadas acima que parte significativa de tais cursos foram ofertados em caráter excepcional, formando turmas pontuais que surgem para atender a uma demanda específica. Esse dado é certamente relevante, tendo em vista que a maior parte dos professores que atuam no Ensino Médio lecionando Sociologia não possui formação inicial nas Ciências Sociais, de modo que tais cursos surgiram como uma oportunidade real para que adquirissem formação na área que lecionam.

0 que podemos perceber a partir dos dados apresentados é um aumento bastante significativo do número de cursos de formação de professores em Ciências Sociais. Se considerarmos apenas os presenciais, houve um salto de três para dez cursos, o que im- plica num aumento de 233\% no número de cursos. Esse processo foi conduzido essencialmente pelo setor privado, de modo que apenas um dentre os novos cursos surgiu em uma instituição pública de ensino (UFFS). Sendo assim, se até 2007 66\% dos cursos estavam em instituições públicas, essa proporção caiu para 30\% em 2014.

Essa maior clareza sobre o campo de atuação dos egressos da licenciatura em Ciências Sociais/Sociologia aparentemente implicou uma maior demanda pelo curso, o que por sua vez levou a uma maior presença de Instituições de Ensino Superior (IES) Privadas, que buscaram suprir uma demanda que cresceu em uma velocidade maior que a oferta do setor público.

Também junto às IES públicas houve um aumento no número de vagas ofertadas, tendo em vista que para o vestibular 2007 na UFSC havia uma oferta total de 80 vagas para o curso de Ciências Sociais, e em 2014 esse número passou para $90^{10}$; porém esse aumento foi bastante discreto se considerarmos o crescimento ocorrido no setor privado.

Os pontos acima elencados são relevantes para o delineamento do que estou denominando de expansão conservadora, pois com isso quero dizer duas coisas a se examinar separadamente:

a) ao situar que há uma expansão em curso referente às graduações em Ciências Sociais, especialmente às licenciaturas, e que

9. Trata-se de um programa de caráter emergencial que visa a atender ao que está disposto no artigo 11, inciso III do Decreto $\mathrm{n}^{\circ}$ 6.755, de 29 de janeiro de 2009, que foi implantado em regime de colaboração entre a Coordenação de Aperfeiçoamento de Pessoal de Ensino Superior (CAPES), os estados, os municípios, o Distrito Federal e as Instituições de Educação Superior (IES). Esse programa fomenta a oferta de turmas especiais em cursos de licenciatura, segunda licenciatura e formação pedagógica.

10. Esses números incluem os turnos diurno e noturno, havendo a especificidade na UFSC de que a entrada para o bacharelado e a licenciatura é conjunta, cabendo aos alunos escolherem no decorrer do curso a habilitação que pretendem seguir, ainda que segundo a pesquisa apresentada por Mick et al. (2012) a maior parte dos alunos acabem por realizar as duas habilitações. 
esse fenômeno foi desencadeado sobretudo pela reintrodução da Sociologia no currículo escolar, acabo por afirmar também que houve um período de relativa estagnação no número de cursos criados de Ciências Sociais, justamente num momento de acelerado crescimento quantitativo do Ensino Superior brasileiro, principalmente na década de 1990. Observou-se em período recente em SC, anterior à reintrodução da Sociologia no Ensino Médio, até mesmo o fechamento de cursos de Ciências Sociais, como o da UNIPLAC que fora criado ainda nos anos de $1970^{11}$, e no Brasil observou-se entre 1992 e 1994 uma redução de 28\% na oferta do curso de Ciências Sociais (SÁ, 2000). Busco destacar, portanto, o caráter idiossincrático da expansão do curso de Ciências Sociais, que ocorreu em período tardio se comparada com a expansão mais ampla que ocorreu no Ensino Superior brasileiro, relacionando-se com as transformações ocorridas na Educação Básica.

b) o qualificativo "conservadora" não se coloca como mera retórica no texto, pois compreendo que a expansão do ensino pode se dar de maneira democrática, buscando garantir o amplo acesso à educação pública e de qualidade, ou de maneira conservadora, transformando o direito à educação em mercadoria. Neste caso, é importante destacar que em Santa Catarina muitas licenciaturas em Ciências Sociais surgiram para assumir uma demanda emergencial, e a carga horária desses cursos tende a se situar próxima ao mínimo que as diretrizes para as licenciaturas indicavam até então (2.800 horas), porém aquém do que é indicado pelo Parecer $\mathrm{n}^{\circ}$ CNE/CP de $1^{\circ}$ de julho de 2015, um mínimo de 3.200 horas para a formação inicial de professores no Brasil. Portanto, o qualitativo "conservadora" aponta para uma expansão assentada no ensino privado e em cursos normalmente "aligeirados", voltados para atender a uma demanda emergencial.

Esses dois aspectos que trago, portanto, remetem a um elemento mais descritivo (a expansão) e a outro mais analítico (o seu caráter conservador), mas que não se desassociam. Esse arranjo no caso dos cursos de Ciências Sociais só se faz possível ante a uma conjuntura específica, na qual há uma maior clareza sobre o campo de atuação dos egressos do curso; não à toa, a mesma expansão não foi verificada com relação aos cursos de bacharelado em Ciências Sociais.

Acredito, portanto, que presenciamos nos cursos de formação de professores de Ciências Sociais uma expansão tardia, tendo em vista que a partir de meados dos anos de 1990 houve uma rápida e acelerada expansão desse setor (NEVES; RAIZER; FACHINETTO, 2007) e, como já foi demonstrado aqui, o mesmo não ocorreu nos cursos analisados.

Outro fator interessante que mereceria ser destacado é a presença massiva de cursos que se afirmam como licenciatura em Sociologia e não em Ciências Sociais, o que é um fenômeno recente, tendo em vista que dentro da tradição intelectual que se instaurou no Brasil, ao menos desde a criação dos primeiros cursos no Brasil ${ }^{12}$, a referência mais recorrente é ao campo das

11. A licenciatura em Ciências Sociais obteve autorização para seu funcionamento pelo Parecer $n^{\circ} 48 / 70 /$ CEES/SC, de 14 de maio de 1970, homologado pelo Decreto Presidencial $n^{\circ}$ 66.849/70, de 6 de julho de 1970, e reconhecido pelo Decreto no 79.943/77, de 13 de julho de 1977.

12. Os primeiros cursos de Ciências Sociais criados no Brasil foram em São Paulo, primeiramente na Escola Livre de Sociologia e Política em 1933, e no ano seguinte na Universidade de São Paulo. Em 1935 foi criado outro na Universidade do Distrito Federal no Rio de Janeiro, porém foi uma curta experiência que durou até 1939. 
Ciências Sociais, o que inclui além da Sociologia também a Ciência Política.

A demarcação do curso em termos de nomenclatura enquanto licenciatura em Sociologia indica uma ligação direta com a disciplina escolar, apontando para uma instrumentalização do curso, o que invisibiliza num primeiro momento a articulação com as demais Ciências Sociais, e em um segundo a própria questão da pesquisa. É importante frisar que segundo as diretrizes curriculares nacionais para os cursos de Ciências Sociais (Parecer CNE/CES $n^{\circ}$ 492/2001) a articulação entre as três áreas de conhecimento básicas de tais cursos (Antropologia, Ciência Política e Sociologia) deve ser garantida, assim como a formação para a pesquisa que também deve estar presente na formação docente.

Entretanto, ao analisarmos as grades curriculares mesmo daquelas que se afirmam como licenciaturas em Sociologia, a Antropologia e a Ciência Política se fazem presentes, o que nos indica que os modelos formativos que se consolidaram como hegemônicos nesse campo são reproduzidos em alguma medida, ainda que haja um menor enfoque na questão da pesquisa, que surge de forma bastante marginal, o que é reforçado pela ausência da oferta do curso de Bacharelado por essas instituições, bem como de pós-graduação stricto sensu na mesma área de conhecimento, o que pode nos indicar uma frágil formação acadêmica.

Pode-se notar certa homogeneidade nos cursos existentes a partir da sua carga horária total, tendo em vista que os novos cursos tendem a ter uma carga horária próxima das 2800 horas. Considerando apenas os presenciais, temos o seguinte cenário, em horas: UC - 2820; UNIDAVI - 2820; UNOCHAPECÓ - 2850; UNIVILLE - 2820; UNOESC - 2850; UNISUL - 2805; a exce- ção é o curso da UFFS, que é o único curso público entre os criados a partir de 2008 e possui 3285 horas.

Obviamente não quero dizer com isso que uma maior carga horária implique necessariamente um curso de melhor qualidade, porém fica evidente que há uma oferta de cursos cuja carga horária aproxima-se do mínimo indicado no Parecer CNE/CP $n^{\circ}$ 28/2001, porém fica abaixo da carga horária mínima indicada pelas novas diretrizes para a formação inicial de professores, como já indiquei anteriormente. Nos cursos anteriores à reintrodução da Sociologia, a carga horária chega a 3474, o que tende a indicar uma maior carga horária voltada para a pesquisa.

Essas questões apontam para a complexifıcação do campo acadêmico e da formação docente em Ciências Sociais em SC, o que acredito ser uma tendência mais geral no Brasil que tem se dinamizado a partir da reintrodução da Sociologia no currículo escolar. 0 que gera uma maior diversificação na oferta, bem como uma maior estratificação em termos qualitativos de tais cursos, o que não será analisado aqui tendo em vista os limites dos dados com os quais estamos lidando neste momento. Nos termos postos por Martins (2009, p. 28-29),

Nesses últimos quarenta anos, o ensino superior brasileiro se estruturou como um campo acadêmico complexo, heterogêneo, no qual as instituições passaram a ocupar posições dominantes e/ou dominadas em função dos critérios específicos que definem o prestígio e o reconhecimento dos estabelecimentos. Não seria de todo incorreto levantar a suposição de que houve, nas últimas décadas, um processo de hierarquização acadêmica no interior do campo do ensino superior brasileiro. 
Dessa forma, algumas universidades públicas (federais e estaduais) e determinadas universidades privadas (geralmente as confessionais) se organizaram gradualmente, de modo a se aproximarem de um modelo acadêmico neo-humboldtiano. Essas instituições criaram estruturas acadêmicas que propiciaram a produção científıca institucionalizada, desenvolveram cursos de pós-graduação stricto sensu, promoveram a profissionalização da carreira acadêmica, adotaram o regime de tempo integral para seus docentes, preservaram a liberdade acadêmica, associaram as atividades de ensino e pesquisa, implantaram programas de iniciação cientifica em parceria com agências de fomento nacionais. Em 2006, as universidades públicas federais e estaduais concentravam 70\% dos docentes de tempo integral e 64\% dos doutores no pais (Scott, 2006; Sguissardi, 2005; Casper \& Humbolt, 1997; Charle \&t Verger, 1994).

Por sua vez, as instituições privadas de perfil empresarial estruturaram atividades que guardam certas afınidades acadêmicas com o modelo neo-napoleônico. De modo geral, essas instituições basicamente estão voltadas para uma estrita formação profissional e empregam professores horistas com pequeno volume de titulação acadêmica, que se dedicam em sua maior parte às atividades de ensino. Predomina em seu interior uma ausência de estruturas consolidadas de pesquisa e de pós-graduação stricto sensu. As instituições particulares com fins lucrativos concentram apenas 14\% dos docentes de tempo integral e $16 \%$ dos doutores do país.

No cenário analisado outro fator relevante constatado diz respeito à dispersão espacial de tais cursos, o que inclui um grande número de cidades atendidas pelos polos de EaD. A UCS possui 10 polos, a ULBRA três, a UNIASSELVI 17, a UNOPAR 18.
Houve, desse modo, uma intensa interiorização da oferta de licenciatura em Ciências Sociais/Sociologia em SC, chegando não apenas a cidades de grande e médio porte, como também a pequenos municípios.

Por fim, gostaria de apontar para mais uma singularidade do cenário encontrado: se por um lado essa expansão tardia examinada seguiu a tendência mais geral encontrada no Ensino Superior brasileiro, ao ser predominantemente marcada pelo setor privado, por outro o que foi observado como mais geral no Brasil, que é a oferta concentrada em instituições não universitárias, não se seguiu na formação docente em Ciências Sociais em SC, tendo em vista que, se considerarmos apenas os cursos presenciais, 90\% estão alocados em instituições universitárias. Apesar das profundas assimetrias que podem ser observadas entre tais instituições, acredito que a formação universitária é um fator relevante, e que demarca ainda algum diferencial na formação inicial docente.

\section{Considerações Finais}

Longe de buscar exaurir a discussão, busquei neste breve artigo apontar para o desenho que têm assumido os cursos de formação de professores em Ciências Sociais, o que foi realizado a partir de um caso particular que se refere ao estado de Santa Catarina.

A hipótese inicial que havia posto de que a reintrodução da Sociologia em nível nacional, a partir da Lei $n^{\circ} 11.684 / 08$, teria um impacto decisivo no processo de expansão do número de tais cursos, se confirmou nos dados acessados, pois de fato após um período de latência houve um incremento exponencial na oferta dessa formação em um curto intervalo de tempo (2008-2014), o que se deu de forma tardia se considerarmos a 
expansão do Ensino Superior brasileiro nos anos de 1990. Chama atenção o fato de que a introdução que foi realizada por meio de uma Lei Complementar Estadual ainda em 1998 não teve o fôlego de impactar os cursos, ao menos não de forma isolada.

Não apenas o período de expansão foi distinto do movimento mais geral que observamos como também se deu de forma menos diversificada, permanecendo como forma prioritária o ensino universitário, ainda que tenha havido a entrada de novos agentes, o que inclui a EaD. Acredito que se a tendência permanecer haverá uma diversificação ainda maior nessa oferta, com ampliação do ensino em instituições não universitárias e na modalidade $\mathrm{EaD}$, seguindo o cenário que encontramos disseminado em outras áreas do conhecimento, consolidando aquilo que aqui foi denominado de expansão conservadora.

Ainda que tenham ganhado fôlego, os cursos que se afırmam como licenciaturas em Sociologia, percebe-se a reprodução de um currículo no qual se articulam as Ciências Sociais, o que está em afınidade com a tradição intelectual que se instaurou no Brasil, tendo em vista que outros arranjos também seriam possiveis com outras áreas de saber (MAGGIE, 2006). Esse direcionamento em termos de nomenclatura, parece indicar, em última instância, a forte afınidade com a dimensão do mercado que assenta esse processo de expansão dos cursos de Ciências Sociais, movido pela tentativa de responder de forma imediata a uma demanda que surge a partir da reintrodução da Sociologia no currículo escolar em nível nacional.
Apesar de dois fatores, a) essa expansão em sua totalidade não representar um real processo de democratização do acesso ao Ensino Superior, mais especificamente ao curso de formação de professores em Ciências Sociais; b) não haver ainda elementos suficientes para avaliar a qualidade da formação ofertada pelos cursos mais recentemente criados; penso que se podem tecer algumas ponderações otimistas desse cenário. A primeira e mais evidente é que tal expansão pode minimizar o atual cenário no qual a maior parte dos professores que ensinam Sociologia nas escolas não possuem formação nas Ciências Sociais; e a segunda é que a criação de novos cursos tende a dinamizar o próprio campo das Ciências Sociais em nível local, com o incremento do número de alunos e de professores na área.

Por fim, gostaria de afirmar que mesmo diante de uma expansão capitaneada pelo setor privado as Universidades Públicas continuam exercendo um papel fundamental, principalmente no processo de produção de difusão do conhecimento. No caso de SC fica evidente, tendo em vista que apenas a UFSC possui atualmente pós-graduação stricto sensu nas Ciências Sociais, que a formação ofertada por tais instituições tende a ser aquela recebida pelos formadores que atuam nas instituições privadas $^{13}$. Desse modo, o debate promovido pela Universidade Pública tende a circular para além de seus muros, contagiando de alguma forma essa nova geração de professores de Ciências Sociais que se formam em outras instituições.

13. Não foi levantado o perfil do corpo docente de tais cursos, o que estava além do escopo deste trabalho, todavia conforme podemos verificar no site da CAPES < http://www.capes.gov.br> a maior parte das pós-graduações stricto sensu no Brasil concentram-se em instituições públicas, de modo que tendencialmente os professores que atuam nas IES privadas também possuem formação nas IES públicas. 


\section{Referências}

BRASIL. Lei no 11.648, de 2 de junho de 2008 . Altera o art. 36 da lei no 9.394 , de 20 de dezembro de 1996, que estabelece as diretrizes e bases da educação nacional, para incluir a Filosofia e a Sociologia como disciplinas obrigatórias nos currículos do ensino médio. Diário Oficial da União, Brasília, 3 de junho de 2008.

Parecer CNE/CEB no 38, de 16 de agosto de 2006. Inclusão obrigatória das disciplinas de Filosofia e Sociologia no currículo do Ensino Médio. Diário Oficial da União, Brasília, 14 de agosto de 2006.

. Parecer CNE/CES no 492, de 3 de abril de 2001. Diretrizes Curriculares Nacionais dos cursos de Filosofıa, História, Geografia, Serviço Social, Comunicação Social, Ciências Sociais, Letras, Biblioteconomia, Arquivologia e Museologia. Diário Oficial da União, Brasília, 9 de julho de 2001.

Parecer CNE/CP $n^{\circ}$ 2, de $9^{\circ}$ de junho de 2015. Diretrizes Curriculares Nacionais para a Formação Inicial e Continuada dos Profissionais do Magistério da Educação Básica. Brasília, Diário Oficial da União, Brasília, 25 de junho de 2015.

Parecer CNE/CP no 28, de 2 de outubro de 2001. Dá nova redação ao Parecer CNE/CP 21/2001, que estabelece a duração e a carga horária dos cursos de Formação de Professores da Educação Básica, em nível superior, curso de licenciatura, de graduação plena. Brasília, Diário Oficial da União, 18 de janeiro de 2001.

Resolução CNE/CES no 3, de 14 de outubro de 2010. Regulamenta o Art. 52 da Lei no 9.394, de 20 de dezembro de 1996, e dispõe sobre normas e procedimentos para credenciamento e recredenciamento de universidades do Sistema Federal de Ensino. Brasília, Diário Oficial da União, 15 de outubro de 2010.

COAN, M. A Sociologia no Ensino Médio, o material didático e a categoria trabalho. 2006. 356f. Dissertação (Mestrado em Educação) - Centro de Ciências da Educação, Universidade Federal de Santa Catarina, Florianópolis, 2006.
DAROS, M. das D. NASCIMENTO, C. D. do; DANIEL, L. S. A sociologia na formação dos professores catarinenses. In: 23 ${ }^{a}$ Reunião da ANPED, 2000, Caxambú. Anais da 23 ${ }^{\text {a }}$ Reunião Anual da ANPED. Caxambú, 2000.

ERAS, L. W. A produção do conhecimento recente sobre o ensino de sociologia/ciências sociais na educação básica no formato de livros coletâneas (2008-2013): sociologias e trajetórias. 2014. 331f. Tese (Doutorado em Sociologia) - Setor de Ciências Humanas, Letras e Artes, Universidade Federal do Paraná, Curitiba, 2014.

CARIDÁ, A. C. B. B. Sociologia no ensino médio: diretrizes curriculares e trabalho docente. 2014. Dissertação (Mestrado em Sociologia e Politica) - Centro de Filosofia e Ciências Humanas, Universidade Federal de Santa Catarina, Florianópolis, 2014.

CARVALHO, L. M. G. X.; MATTOS, S. S. Sociólogos \&t Sociologia: história das suas entidades no Brasil e no mundo. São Paulo: Anita Garibaldi, 2005.

CARVALHO FILHO, J. L. L'institutionnalisation de la sociologie dans l'enseignement secondaire au Brésil. Incursions, s/v, n. 8, p. 13-37, 2013.

DINIZ-PEREIRA, J. E. As licenciaturas e as novas políticas educacionais para a formação docente. Educ. Soc., v. 20, n. 68, p. 109-125, 1999.

HANDFAS, A. A formação do professor de Sociologia. In: ; OLIVEIRA, L. F. (Org.). A Sociologia vai à escola: história, ensino e docência. Rio de Janeiro: Quartet, 2009.

Formação dos professores de Sociologia: um debate em aberto. In: ; MAÇAIRA, J. P. (Org.). Dilemas e Perspectivas da Sociologia na Educação Básica. Rio de Janeiro: e-papers, p. 1125, 2012.

ISAMBERT-JAMATI, V.; MAUCORPS, J. G. La Sociologie de L'Éducation: tendances actuelles de la recherche et bibliographie. La Sociologie Contemporaine. v. 20, n. 1, p. 5-49, 1972. 
JINKINGS, N. A Sociologia em escolas de Santa Catarina. Inter-legere, s/v, n. 9, p. 103-117, 2011.

LÜCHMANN, L. H. H. 0 curso de Ciências Sociais da UFSC. Mosaico Social, v. 1, n. 1, p. 7-68, 2002.

MARTINS, C. B. A Reforma Universitária de 1968 e a abertura para o ensino superior privado do Brasil. Educação \&t Sociedade, v. 30, n. 106, p. 15-35, 2009.

MARTINS, C. B.; WEBER, S. Sociologia da Educação: democratização e cidadania. In: MARTINS, C. B.; MARTINS, H. H. T. de S. Horizontes das Ciências Sociais: Sociologia. São Paulo: ANPOCS, p. 131-201, 2010.

MICK, J.; DIAMICO, M. de S. ; LUZ, J. R. 0 perfil do egresso do curso de Ciências Sociais da UFSC (2000-2009). Mosaico Social, v. VI, p. 347-386, 2012.

MORAES, A. C. Ensino de Sociologia: periodização e campanha pela obrigatoriedade. Cadernos CEDES, v. 31, p. 359-382, 2011.

. Licenciatura em ciências sociais e ensino de sociologia: entre o balanço e o relato. Tempo soc., v. 15, n. 1, p. 5-20, 2003.

NEUHOLD, R. dos R. Sociologia do ensino de Sociologia: os debates acadêmicos sobre a constituição de uma disciplina escolar. 2014. Tese (Doutorado em Educação) - Faculdade de Educação, Universidade de São Paulo, São Paulo, 2014.

NEVES, C. E. B. Estudos sociológicos sobre educação no Brasil. In: MICELI, S. (Org.). 0 que ler na ciência social brasileira 1970-2002. São Paulo; Brasília: Editora Sumaré; CAPES, v. IV, p. 351437, 2002.

NEVES, C. E. B.; RAIZER, L. FACHINETTO, R. F. Acesso, expansão e equidade na educação superior: novos desafios para a política educacional brasileira. Sociologias, v. 9, n. 17, p. 124-157, 2007.

OLIVEIRA, A. A formação inicial de professores de Sociologia no Nordeste: alguns breves apontamentos. Pesquiseduca, v. 6, n. 12, p. 285-299, 2014 a.
. Desafios e singularidades do estágio supervisionado na formação de professores de Ciências Sociais. Teoria e Prática da Educação, v. 24, n. 47, p. 195-216, 2014b.

. Formação de professores de Ciências Sociais ante às políticas educacionais. Crítica e Sociedade: revista de cultura política, v. 3 , n. 2, p. 132-152, 2013 .

. Revisitando a história do ensino de Sociologia na Educação Básica. Acta Scientiarum. Education, v. 35, n. 2, p. 179-189, 2013 b.

. Sociologie de l'éducation au Brésil: tendances historiques et contemporaines. Incursions, s/v, n. 8, p. 75-93, 2013c.

OLIVEIRA, A.; BRUM, C. Ciências Sociais à Distância: apontamentos sobre os desafios da formação de professores no Brasil. 0 público e o privado, s/v, n. 24, p. 26-39, 2014.

OLIVEIRA, A.; LIMA, V. S. Formação de professores em Ciências Sociais: desafios e possibilidades a partir do estágio e do PIBID. In: GONÇALVES, D. G. (Org.). Sociologia e juventude no Ensino Médio: formação, PIBID e outras experiências. Campinas: Pontes Editores, p. 139-151, 2013.

OLIVEIRA, A.; SILVA, C. F. Mapeamento da Sociologia da Educação no Brasil: análise de um campo em construção. Atos de pesquisa em educação, v. 9, n. 2, p. 289-315, 2014.

ROSA, M. 0 trabalho docente com a disciplina de Sociologia: algumas reflexões sobre o ser professor no ensino médio da rede pública de Santa Catarina. 2009. Dissertação (Mestrado em Educação) - Centro de Ciências da Educação, Universidade Federal de Santa Catarina, Florianópolis, 2009.

SÁ, G. B. de. Os dilemas das licenciaturas no curso de Ciências Sociais: um estudo de caso na UNIPLAC-Lages/SC. 2000. 102f. Dissertação (Mestrado em Educação) - Centro de Ciências da Educação, Universidade Federal de Santa Catarina, Florianópolis, 2000.

SARANDY, F. Ensino de Sociologia: insulamento e invisibilidade de uma disciplina. In: FIGUEIRDO, 
A. V.; OLIVEIRA, L. F. de; PINTO, N. M. (Org.). Sociologia na sala de aula. Rio de Janeiro: Imperial Novo Milênio, p. 47-72, 2012.

SAVIANI, D. História das ideias pedagógicas no Brasil. Campinas: Autores Associados, 2011.

SILVA, I. L. F. . 0 ensino das ciências sociais/sociologia no Brasil: histórico e perspectivas. In: MORAES, A. C. de (Org.). Coleção Explorando o Ensino de Sociologia. Brasília: MEC, p. 23-31, 2010.

TAKAGI, C. T. T. Formação de professores de Sociologia do Ensino Médio: um estudo sobre o currículo do curso de ciências sociais na Universidade de São Paulo. 2013. Tese (Doutorado em Educação) - Faculdade de Educação, Universidade de São Paulo, São Paulo, 2013.

UNIVERSIDADE FEDERAL DE SANTA CATARINA - UFSC. Boletim de Ciências Sociais. s/v, no 17, 1980.

Curso de Ciências Sociais - Projeto Político Pedagógico. Florianópolis, 2006.

WEBER, S. Profissionalização docente e políticas públicas no Brasil. Educ. Soc., v.24, n. 85, p. 11251154, 2003. 
RESUMO

A expansão do Ensino Superior no Brasil não é um fenômeno recente; desde os anos de 1970 ela vem ocorrendo de forma crescente, concentrada principalmente nas instituições privadas. No entanto, no caso dos cursos de Ciências Sociais isso parece ser algo recente, que tem sido dinamizado pela reintrodução da Sociologia no Ensino Médio. Analiso neste artigo o processo de expansão das licenciaturas em Ciências Sociais/Sociologia em Santa Catarina, a partir dos dados fornecidos pela plataforma e-MEC <http://emec.mec.gov.br/>, considerando tanto as singularidades envolvidas nesse estado como as questões gerais que se aplicam também ao resto do país. Compreendo que ocorreu uma expansão conservadora, concentrada nas instituições privadas de ensino, com uma presença crescente da Educação a Distância.

\section{PALAVRAS-CHAVE}

Ensino de Sociologia. Formação de Professores em Ciências Sociais. Sociologia da Educação. Ensino Superior.

\section{ABSTRACT}

The expansion of higher education in Brazil is not a recent phenomenon, since the 1970s it has been happening increasingly, concentrated mainly in private institutions, however in the case of Social Sciences courses this seems to be a recent phenomenon, which has been promoted by the reintroduction of Sociology in high school. I analyze in this article the process of expansion of teacher training courses in Social Science / Sociology in Santa Catarina, which conducted from data provided by the platform e-MEC <http://emec. mec.gov.br/> considering both the singularities involved there as the general issues which apply to the rest of the country. I understand that there was a conservative expansion, concentrated private educational institutions, with an increasing presence of distance education.

\section{KEYWORDS}

Sociology of Education. Teacher Training in Social Sciences. Sociology of Education. Higher Education. 